\title{
MODEL PENCEGAHAN KANKER SERVIKS BERDASARKAN KARATERISTIK SOSIAL BUDAYA PADA WANITADI DESA PAGELARAN KABUPATEN MALANG
}

\author{
Ririn Harini \\ Jurusan Ilmu Keperawatan, Fakultas Ilmu Kesehatan, Universitas Muhammadiyah Malang Malang \\ E-mail :webmaster@unix.umm.ac.id
}

\begin{abstract}
The development of prevention efforts to reduce cervical cancer among high risk women is part of maternity nursing and particularly in the field of women's reproductive health care. Applications of nursing and health-care procedures aimed at the conservation, promotion and restoration of individual health and a community group that is part of the effort to develop a model of nursing matenitas. The role of health promotion in this research is to empower the community through awareness raising in the cultural aspects of society. The study was conducted to achieve several objectives, namely to identify cultural characteristics factors, social support factors in women with high risk of cervical cancer, analyzing the forms and media promotion in high risk women with cervical cancer, designing primary and secondary prevention models of cervical cancer and Analyze implementation of primary and secondary prevention in women high risk of cervical cancer. The type of research used in this research is descriptive analytic research. Descriptive analytic research is needed to identify women data with high risk of cervical cancer, cultural factors, and social support factors. The population in the study of 280 women of childbearing age (WUS) in Kab. Poor. The sample used after the measured sample size is 99 fertile age women who married at the age of less than 20 years. The sample was taken by simple random sampling. The results showed that the characteristics of respondents based on predisposing factors in early detection of cervical cancer include age, education, occupation, income, marital status, knowledge and attitude contributed to knowledge and behavior of WUS in preventing the occurrence of cervical cancer.
\end{abstract}

\section{Keywords : Prevention model, cervical cancer, socio-cultural characteristics}

\begin{abstract}
Abstrak : Pengembangan upaya pencegahan untuk menurunkan penyakit kanker serviks terhadap kelompok wanita resiko tinggi merupakan bagian dari keperawatan maternitas dan khususnya bidang perawatan kesehatan reproduksi wanita (women health). Aplikasi dari keperawatan dan prosedur pelayanan kesehatan yang ditujukan untuk konservasi, promosi, dan restorasi kesehatan individu dan kelompok yang dilakukan di masyarakat yang merupakan bagian dari upaya pengembangan model keperawatan matenitas. Peran promosi kesehatan dalam penelitian ini adalah memandirikan masyarakat melalui penimgkatan kesadaran dalam pendekatan aspek budaya masyarakat. Penelitian ini dilakukan untuk mencapai beberapa tujuan, yaitu Mengidentifikasi faktor karateristik budaya, faktor dukungan sosial pada wanita dengan resiko tinggi penyakit kanker serviks, Menganalisa bentuk dan media promosi pada wanita resiko tinggi dengan penyakit kanker serviks, Merancang model pencegahan primer dan sekunder kanker servik dan Menganalisa implementasi pencegahan primer dan sekunder pada wanita resiko tinggi kanker serviks. Jenis penelitian yang digunakan dalam penelitian ini adalah penelitian deskriptif analitik. Penelitian deskriptif analitik diperlukan untuk mengidentifikasi data wanita dengan resiko tinggi kanker serviks, faktor budaya, dan faktor dukungan sosial. Populasi dalam penelitian 280 wanita usia subur (WUS) di Kabupaten Malang. Sampel yang digunakan setelah diukur besar sampelnya adalah 99 wanita usia subur yang menikah pada usia kurang dari 20 tahun. Sampel penelitian diambil secara simple random sampling. Hasil penelitian menunjukkan bahwa karakteristik responden berdasarkan faktor predisposisi dalam deteksi dini kanker serviks meliputi umur, pendidikan, pekerjaan, penghasilan, status perkawinan, pengetahuan dan sikap memberikan kontribusi terhadap pengetahuan dan perilaku WUS dalam mencegah terjadinya kanker serviks.
\end{abstract}

Kata Kunci : Model pencegahan, kanker serviks, karateristik sosial budaya

\section{PENDAHULUAN}

Pengembangan upaya pencegahan untuk menurunkan penyakit kanker serviks terhadap kelompok wanita resiko tinggi merupakan bagian dari keperawatan maternitas dan khususnya bidang perawatan kesehatan reproduksi wanita (women health). Martin, Reeder, Griffin (2013) mengatakan bahwa "Woman Health adalah keadaan sejahtera fisik, mental dan sosial secara utuh pada wanita, yang tidak semata-mata bebas dari 
penyakit atau kecacatan, dalam semua hal yang berkaitan dengan sistem reproduksi, serta fungsi dan prosesnya". Aplikasi dari keperawatan dan prosedur pelayanan kesehatan yang ditujukan untuk konservasi, promosi, dan restorasi kesehatan individu dan kelompok yang dilakukan di masyarakat yang merupakan bagian dari upaya pengembangan model keperawatan maternitas. Peran promosi kesehatan dalam penelitian ini adalah memandirikan masyarakat melalui peningkatan kesadaran dalam pendekatan aspek budaya masyarakat.

Upaya pencegahan kanker serviks dengan deteksi dini pap smear memang sudah dilakukan di berbagai pusat pelayanan kesehatan tetapi jika dilihat pada state of the art adanya perbedaan dalam penelitian ini memandang karateristik sosial budaya lebih menyesuaikan dengan kondisi karateristik sosial budaya di masyarakat tersebut seperti tingkat pendidikan, pekerjaan / struktur agraris pedesaan, sistem nilai budaya masyarakat serta hubungan sosial masyarakat. Kelompok yang mudah terinfeksi HPV termasuk dalam kelompok resiko tinggi, yaitu : Wanita yang melakukan hubungan seksual diwaktu muda antara usia 14-16 tahun. Wanita remaja berusia 14-16 tahun masih mengalami perubahan hormon yang besar. Selama masa pubertas, kondisi leher rahimnya masih immature (belum berkembang sempurna) dan sel-sel leher rahimnya masih sangat aktif. Oleh karena itu penelitian ini bertujuan untuk mengembangkan Model pencegahan kanker servik berdasarkan karakteristik sosial budaya pada wanita di pedesaan untuk menurunkan penyakit kanker serviks pada kelompok resiko tinggi wanita dengan perkawinan usia muda.

Penelitian ini dilakukan untuk :

a. Mengidentifikasi faktor karateristik budaya, faktor dukungan sosial pada wanita dengan resiko tinggi penyakit kanker serviks;

b. Menganalisa bentuk dan media promosi pada wanita resiko tinggi denga penyakit;

c. Merancang model pencegahan primer dan sekunder kanker serviks;

d. Menganalisa implementasi pencegahan primer dan sekunderpada wanita resiko tinggi kanker serviks.

Manfaat dari penelitian ini dapat meningkatkan peran perawat maternitas dalam meningkatkan adaptasi yang sehat pada wanita usia subur khususnya dengan resiko tinggi penyakit kanker serviks. Sebagai sarana informasi bagi masyarakat khususnya wanita dengan resiko tinggi kanker serviks yang awam dengan berbagai informasi karena keterbatasan pengetahuan,pendidikan dan pengalaman. Dapat mendorong sikap positif mengenai deteksi dini dengan pap smear sebagai ungkapan identitas feminim dan suatu proses yang normal dan sehat. Perawat dapat memfasilitasi upaya wanita resiko tinggi kanker serviks dan keluarga untuk mendapatkan kesehatan dan kebutuhan kesejahteraan, meningkatkan pendidikan dan penelitian di klinik dan dilapangan.

\section{METODE PENELITIAN}

Kegiatan penelitian dilakukan selama satu tahun dengan mengidentifikasi faktor resiko, faktor budaya, faktor dukungan sosial dengan jenis penelitian yang digunakan dalam penelitian ini adalah penelitian deskriptif analitik. Tempat penelitian untuk implementasi model pengembangan layanan kesehatan adalah di wilayah kerja puskesmas pagelaran Kabupaten Malang. Sedangkan metode analisa data dengan cara mengolah data secara univariat, bivariat, dan multivariat (Nursalam, 2014).

Populasi dalam penelitian 280 wanita usia subur (WUS) di Kabupaten Malang. Sampel yang digunakan setelah diukur besar sampelnya adalah wanita usia subur yang menikah pada usia kurang dari 20 tahun. Sampel penelitian diambil secara simple random sampling. Sedangkan variabel dalam penelitian ini adalah identifikasi wanita dengan kanker serviks dengan mempertimbangkan faktor dukungan sosial, predisposisi, pemungkin dan penguat.

Prosedur penelitian ini dilakukan dengan mengidentifikasi wanita dengan resiko tinggi penyakit kanker serviks, faktor budaya, faktor dukungan sosial. Kemudian menyiapkan perijinan penelitian di Dinkes Kabupaten. Malang. Ijin penelitian ini sebagai syarat untuk mendapatkan letter of acceptance pelaksanaan penelitian dan selanjutnya melakukan analisa data terkait data wanita yang masuk dalam resiko tinggi kanker serviks, data faktor sosial budaya dan dukungan sosial.

\section{HASIL PENELITIAN}

Pada kelompok umur terbesar berada pada umur $\geq 35$ tahun yaitu sebanyak 55 orang (56\%) pada rentang usia 35 - 50 tahun, dan terkecil pada umur < 35 tahun yaitu sebanyak 44 orang (44\%) dalam rentang usia 20-34 tahun. Sedangkan jumlah terbesar pada tingkat pendidikan WUS pada tingkat menengah yaitu sebanyak 44 orang (45\%), dan pada tingkat rendah yaitu sebanyak 36 orang $(36 \%)$ dan tingkat tinggi yaitu sebanyak 19 orang (19\%). Pada karateristik responden 
berdasarkan jenis pekerjaan sebagian besar WUS tidak bekerja yaitu sebanyak 81 orang $(82 \%)$, dan jumlah WUS yang bekerja hanya sebanyak 18 orang (18\%). Penelitian ini menunjukkan tingkat penghasilan WUS per bulan yang terbesar pada tingkat penghasilan rendah yaitu sebanyak 70 orang $(71 \%)$, ada tingkat tinggi yaitu sebanyak 29 orang (29\%). Untuk status perkawinan WUS dengan jumlah terbesar pada status menikah yaitu sebanyak 94 orang (95\%), dan jumlah terendah dengan status tidak menikah (janda) yaitu sebanyak 5 orang $(5 \%)$.

\section{PEMBAHASAN}

Umur adalah lamanya hidup yang dilalui terhitung mulai saat dilahirkan sampai saat dilakukan penelitian. Umur responden pada penelitian ini berada pada rentang usia paling rendah 20 tahun dan paling tinggi 50 tahun. Rerata umur responden adalah umur < 35 tahun dan $\geq 35$ tahun. Menurut peneliti usia seseorang sangat mempengaruhi faktor WUS dalam melakukan deteksi dini kanker serviks karena dalam penelitian ini peneliti meneliti wanita pada kelompok usia dewasa muda dan dalam usia produktif. Dalam Bobak (2015) mengatakan bahwa seseorang akan semakin mudah untuk memanfaatkan waktu untuk mengikuti segala kegiatannya dan berkeinginan untuk melakukan deteksi dini kanker serviks Secara umum tingkat kedewasaan pada usia tua lebih mungkin untuk melakukan berbagai perilaku sehat seperti mengikuti pola hidup sehat dan melakukan pemeriksaan kesehatan secara rutin. Sedangkan tentang faktor pendidikan Azwar (2012) mengatakan bahwa ibu yang mempunyai pendidikan tinggi lebih banyak yang melakukan pemeriksaan deteksi dini kanker serviks yaitu sebanyak $65,3 \%$, dimana pendidikan mempunyai hubungan secara bermakna dengan perilaku melakukan pap smear. Menurut peneliti ada beberapa faktor yang menyebabkan banyaknya WUS yang tidak melakukan deteksi dini kanker serviks di Desa Pagelaran karena masih menggangap bahwa pemeriksaan tersebut masih asing dan dianggap tabu sehingga sulit untuk diterima oleh masyarakat khususnya para wanita. Mayoritas WUS tidak bekerja atau hanya sebagai ibu rumah tangga yaitu sebanyak 81 orang $(82 \%)$. Pada penelitian ini didapatkan bahwa masih banyaknya WUS yang belum melakukan deteksi dini kanker serviks hal ini dipengaruhi oleh tingkat pendapatan dan pengetahuan tentang biaya pap smear. Menurut Subagus (2014) bahwa Pekerjaan adalah kegiatan yang harus dilakukan terutama untuk menunjang kehidupan diri dan kehidupan keluarganya, sedangkan dalam penelitian ini banyak wanita yang bekerja sehingga akan mempengaruhi kesempatan melakukan deteksi dini kanker serviks. Menurut Azwar (2014) bahwa komponen penghasilan masuk dalam komponen predisposing. Komponen ini digunakan untuk menggambarkan fakta, bahwa individu mempunyai kecenderungan yang berbedabeda untuk menggunakan pelayanan kesehatan. Penghasilan merupakan ukuran yang sering digunakan untuk melihat status sosial ekonomi pada suatu kelompok masyarakat. Semakin baik kondisi status ekonomi masyarakat semakin tinggi presentasi yang digunakan untuk pelayanan kesehatan (Subagus, 2014). Sedangkan status perkawinan erat hubungannya dengan dukungan dari pasangan atau anggota keluarga dalam proses pemeriksaan atau pengobatan suatu penyakit. Perhatian dan kasih sayang sangat dibutuhkan dalam menumbuh kembangkan seorang manusia ke arah yang lebih sehat dan cerdas dan berpotensi (Mubarak, 2015). Salah satu faktor yang dapat mempengaruhi seseorang dalam melakukan deteksi dini adalah pengetahuan. Hasil penelitian yang dilakukan oleh Renggalis Maulana (2012) menyatakan bahwa pengetahuan WUS tentang pap smear dipengaruhi oleh faktor pendidikan, pendidikan mempengaruhi proses belajar dan kegunaannya. Pengetahuan adalah hasil dari tahu dan ini menjadi setelah orang melakukan pengindraan terhadap suatu objek tertentu.

\section{KESIMPULAN}

Faktor predisposisi yang dapat mempengaruhi wanita resiko tinggi kanker serviksyaitu faktor umur pada usia $\geq 35$ tahun, pendidikan pada tingkat menengah (tamat SLTA), sebagian besar para wanita tidak bekerja hanya sebagai IRT, sedangkan penghasilan yang diperoleh pada tingkat rendah (< Rp1.882.250,-), status perkawinan sebagian responden pada status menikah sah, pengetahuan pada tingkat yang cukup, dan sikap pada tingkat yang positif. 


\section{DAFTAR PUSTAKA}

Arikunto, 2010. Manajemen Penelitian. Rineka Cipta: Jakarta.

Azwar, S., 2014. Sikap Manusia dan Pengukurannya, Second Edition. Pustaka Pelajar: Yogyakarta.

Bobak .2015. Keperawatan Maternitas. Volume 6. EGC: Jakarta

Green, L., Kreuter, M.W., 2016. Health E ducation Planning, a diagnostic approach, second. ed. Mayfield Publising Company: California.

Subagus. 2011. Promosi Kesehatan melalui pendidikan konseling. Gosyen Publishing: Yogyakarta
Stone SC., McGuire SL., \& Eigsti DG. 2015. Comprehensive Community Health Nursing Family, Aggregate, \& Community Practice, 6nd edition. Philadelphia: Mosby.

Martin, Reeder.2014. Keperawatan Maternitas Kesehatan Wanita, Bayi Dan Kelurga, Volume 1, EGC: Jakarta

Mubarak, C. \& Rozikin, S. 2015. Promosi Kesehatan sebuah Penjelasan Proses belajar mengajar dalam pendidikan. Edisi pertama. Graha ilmu: Yogyakarta. 